Volume 3, Nomor 2, Tahun 2021 Hal 601 - 609

\title{
SOSIALISASI MENGELOLA KEUANGAN USAHA DI PERKUMPULAN PERSATUAN WANITA METHODIST INDONESIA GEREJA METHODIST INDONESIA SUNGAI YORAN BEKASI
}

\author{
Riwandari Juniasti ${ }^{1}$, Edison Siregar ${ }^{2}$ Lis Sintha Oppusunggu, ${ }^{3}$, Fery Tobing ${ }^{4}$ \\ 1.2.3,4 Universitas Kristen Indonesia, Jakarta, Indonesia \\ E-mail : riwandari.juniasti@uki.ac.id; edison.siregar@uki.ac.id; \\ lis.shinta@uki.ac.id; fery.tobing@uki.ac.id
}

\begin{abstract}
Abstrak
Tujuan Pengabdian kepada Masyarakat di Perkumpulan Persatuan Wanita Methodist Indonesia (PWMI) Gereja Methodist Indonesia Sungai Yordan yang beranggotakan ibu rumah tangga adalah memberikan penyuluhan kepada para ibu rumah tangga tersebut tentang mengelola keuangan usaha. Metode pendekatan yang dilakukan adalah memberikan penyuluhan dan edukasi tentang pengenalan usaha/bisnis sampingan dengan modal kecil, Prilaku Konsumen di Era New Normal, Analisis Break Even Point, dan Cara Mengelola Laba Usaha. Hasil dan implikasi dalam kegiatan Pengabdian kepada Masyarakat (PkM) ini adalah ibu rumah tangga yang tergabung dalam PWMI mengenal berbagai jenis bisnis sampingan yang potensial yang dapat dilakukan oleh ibu rumah tangga yang mobilitas terbatasnya terbatas dan dengan modal yang kecil. Mengetahui tantangan apa saja yang akan dihadapi oleh pemilik usaha agar bisa bertahan hidup di tengah perubahan perilaku konsumen/masyarakat dalam memenuhi kebutuhannya pada masa new normal; mendapat bekal pengetahuan dalam menganalisis usaha, break event point dan memperoleh pengetahuan bagaimana mengelola keuntungan/laba usaha agar laba usaha dapat digunakan untuk pengembangan usahanya.
\end{abstract}

Kata kunci : literasi keuangan, ibu rumah tanga, usaha sampingan

\begin{abstract}
The purpose of Community Service at the Association of Indonesian Methodist Women (PWMI) of the Jordan River Indonesian Methodist Church which consists of housewives is to provide counseling to the housewives about managing business finances. The approach method used is to provide counseling and education about the introduction of side businesses with small capital, Consumer Behavior in the New Normal Era, Break-Even Point Analysis, and How to Manage Business Profits. The results and implications of this Community Service (PkM) activity are the housewives who are members of PWMI can recognize various types of potential side businesses that can be carried out by housewives with small capital and whose mobility is limited. Knowing what challenges will be faced by business owners to survive while changing consumer/community behavior in meeting their needs during the new normal; gain knowledge in business analysis, break-even points and gain knowledge on how to manage business profits/profits so that operating profits can be used for business development.
\end{abstract}

Keywords: financial literacy, housewife, side business 
Volume 3, Nomor 2, Tahun 2021 Hal 601 - 609

\section{PENDAHULUAN}

Perekonomian keluarga mengalami dampak selama Pandemi Covid 19. Dampak ini amat dirasakan oleh ibu rumah tangga yang sehari-hari mengatur keuangan keluarga. Hal ini mendorong ibu rumah tangga berusaha mencari usaha sampingan untuk membantu suami mencari nafkah untuk keluarga. Bisnis makanan dan menjual kebutuhan rumah tangga menjadi usaha sampingan yang banyak ditekuni oleh ibu rumah tangga. Awalnya hanya dari mulut kemulut kemudian mencoba menjajaki melalui wa grup, kemudian beralih ke sosial media, dan toko online. Sebenarnya masih banyak bisnis lain yang bisa dilakukan oleh ibu rumah tangga selain bisnis makanan atau menjual kebutuhan keluarga. Ada juga bisnis sampingan yang tidak menggunakan modal misalnya menjadi doorshipper. Atau bisa juga melihat potensi daerah, misalnya bisnis kerajinan tangan dengan material yang banyak dihasilkan atau menjadi potensi daerah, atau membuat makanan yang bahannya berasal dari tanaman yang merupakan hasil dari daerahnya. Misalnya tinggal di daerah yang mudah menghasilkan singkong maka membuat olahan singkong dengan kreatif.

Banyak ibu rumah tangga mempunyai waktu luang, namun tidak dapat memanfaatkan waktu luangnya untuk melakukan satu usaha untuk membantu perekonomian keluarga karena tidak tahu harus melakukan usaha apa. Ada juga ibu rumah tangga yang telah mencoba untuk bisnis namun hasilnya tidak sesuai yang diharapkan sehingga berhenti melanjutkan bisnis tersebut. Padahal untuk membangun bisnis tidak bisa dilakukan hanya dalam satu minggu atau satu bulan bahkan satu tahun. Sebagian ibu rumah tangga juga sudah ada yang berhasil menjalankan usahanya, namun usahanya tidak berkembang karena tidak dapat meningkatkan kreatifitasnya dalam melakukan pemasaran maupun produk. Namun tak sedikit pula yang sudah mampu untuk terus mengembangkan usahanya selalu mempunyai ide-ide cemerlang, namun kesulitan dalam mengelola keuangan keluarga ataupun mengelola SDM yang membantunya.

Permasalahan yang biasanya dihadapi oleh ibu rumah tangga saat ingin 
memulai usaha dan mengembangkan usahanya adalah sebagai karena:

1. Belum mengetahui dengan baik dimana ada peluang bisnis. Masih kurang pengetahuannya mengenai usaha-usaha yang dapat dilakukan di rumah tanpa meninggalkan kewajibannya sebagai ibu rumah tangga.

2. Permasalahan permodalan sering menjadi alasan, padahal saat ini pemerintah sudah banyak membuka akses untuk pengusaha mikro untuk mengembangkan usahanya.

3. Perubahan kedaan selama pandemi juga merupakan satu hal yang wajib dipahami sebelum memulai usaha dan untuk mempertahankan usaha yang sedang dirintis. Ini merupakan tantangan baru yang harus dicari jalan keluarnya. Usaha harus mengikuti perubahan perilaku konsumen yang berubah sebagai dampak adanya pandemi ini. Bahkan menurut Edy Supriyono, dkk (2021) dalam situasi krisis akibat pandemi, tidak hanya usaha saja yang diaktifkan kembali akan tetapi juga mencakup pengelolaan keuangannya juga harus dikendalikan.
4. Pengetahuan dalam menganalisis usaha juga masih rendah. Kurang matangnya rencana bisnis dan belum memahami cara menghitung harga agar pendapatan yang diperoleh dapat mengcover semua biaya-biaya yang telah dikeluarkan sehingga usaha tidak hanya Break Even Point namun juga mendapatkan keuntungan. Christina Irwati Tanan dan Dian Dhamayanti (2020) mengatakan bahwa banyak lagi pencatatan ataupun laporan keuangan yang tidak dilakukan karena dianggap merepotkan. Menurut Susanti, dkk (2020) disaat masa kriris seperti adanya pandemi ini, laporan keuangan menjadi indikator penting dalam mendukung tumbuhnya usaha selain fokus pada pemasaran.

5. Setelah bisa memperoleh laba, belum mengetahui cara bagaimana mengelola keuntungan tersebut. Brigham dan Houston (2009), mengatakan keputusan utama dalam manajemen yang harus diambil oleh suatu bisnis adalah keputusan mengenai pembagian/ penggunaan laba usaha.

6. Masih enggannya memisahkan keuangan keluarga dengan keuangan usaha, yang membuat 
tidak diketahui apakah sebenarnya usaha ini menghasilkan keuntungan atau malah menjadi tambahan biaya. Penelitian yang dilakukan oleh Christina Irwati Tanan dan Dian Dhamayanti (2020) mengatakan bahwa kebanyakan pelaku UMKM belum bisa memisahkan antara uang yang digunakan dalam pengelolaan usaha dan uang yang digunakan dalam memenuhi kebutuhan keluarga, sehingga kondisi keuangan usaha yang ada sering disatukan atau digabungkan dengan keuangan keluarga

Sehingga tujuan dari dilaksanakannya kegiatan pengabdian pada masyarakat (PPM) ini adalah untuk meningkatkan pemahaman ibu rumah tangga didalam membuka, mengembangkan dan mengelola keuangan usaha/bisnis sampingan sebagai ibu rumah tangga didalam menopang keuangan keluarga

\section{METODE PELAKSANAAN}

Kegiatan Pengabdian kepada Masyarakat ini dilakukan dengan cara melakukan sosialisasi dan edukasi kepada anggota PWMI yang terdiri dari ibu rumah tangga.

Pemilihan ibu rumah tangga sebagai sasaran edukasi adalah sesuai dengan SNLKI (Revisit 2017) yang menitikberatkan kegiatan literasi keuangan pada kelompok tertentu. Prioritas sasaran kelompok masyarakat yang perlu mendapatkan literasi keuangan adalah sebagai berikut:

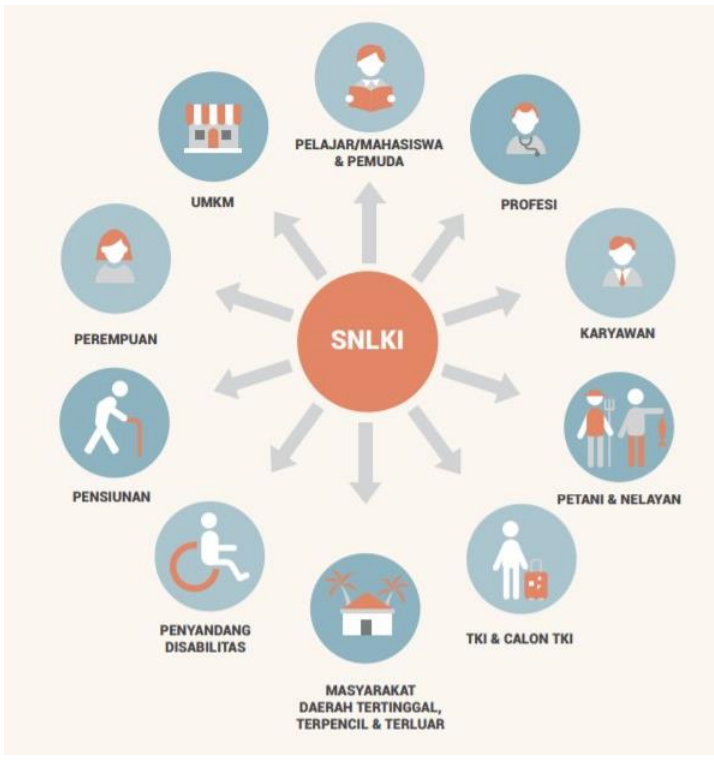

Gambar 1. Sasaran Kegiatan Literasi dan Inklusi Keuangan

Sumber: Strategi Nasional Literasi

Keuangan (Revisit 2017), Otoritas Jasa Keuangan

Pengabdian kepada Masyarakat ini merupakan salah satu cara untuk ikut berperan serta dalam mencapai target pencapaian literasi keuangan masyarakat Indonesia semakin cepat tercapai.

Sebelum pelaksanaan kegiatan dilakukan persiapan-persiapan:

a. Membahas materi yang diperlukan dengan PWMI

b. Menyiapkan flyer agar memudahkan pihak PWMI untuk mengundang anggotanya. 
c. Menyiapkan Zoom Meeting yang akan digunakan, dan mencantumkan linknya dalam flyer. Adapun flyer yang diedarkan adalah sebagai berikut:

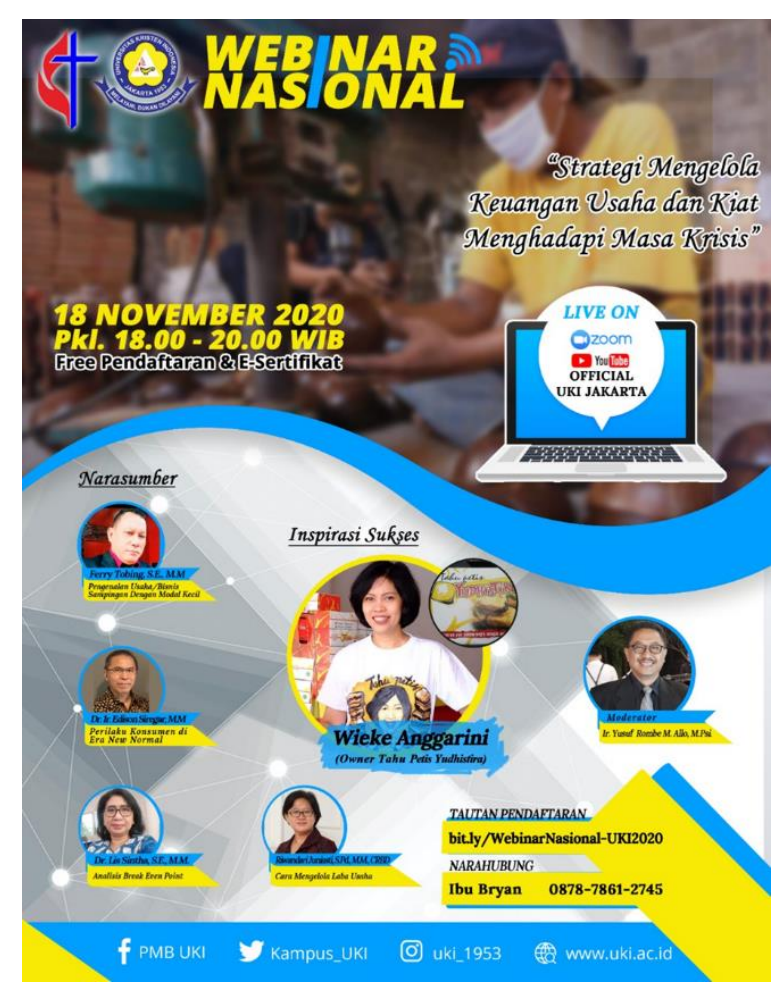

Gambar 2. Flyer PkM

Sumber: Dokumentasi Pribadi

\section{HASIL DAN PEMBAHASAN}

Pengabdian kepada Masyarakat (PkM) ini dihadiri oleh 68 peserta dari PWMI. Berdasarkan tahun kelahiran, peserta yang hadir adalah $54,4 \%$ adalah kelahiran tahun 1996, dan 36,8\% adalah kelahiran tahun 1930-1980, dan tahun 1981 sampai dengan 1995 berjumlah $8,8 \%$.

PkM ini dilaksanakan oleh 4 orang dosen yaitu:
a. Dr. Ir. Edison Siregar, MM
b. Dr. Lis Sintha, SE., MM

c. Fery Tobing, SE., MM

d. Riwandari Juniasti, S.Pd., MM., CRBD

yang keempatnya adalah dosen Program Studi Perbankan Fakultas Vokasi Universitas Kristen Indonesia. Pengabdian masyarakat ini dilakukan secara online melalui Zoom Meeting. Acara ini juga dihari oleh owner tahu petis Yudhistira, Ibu Wieke Anggraini untuk sharing pengalamannya mengelola usaha tahu petis.

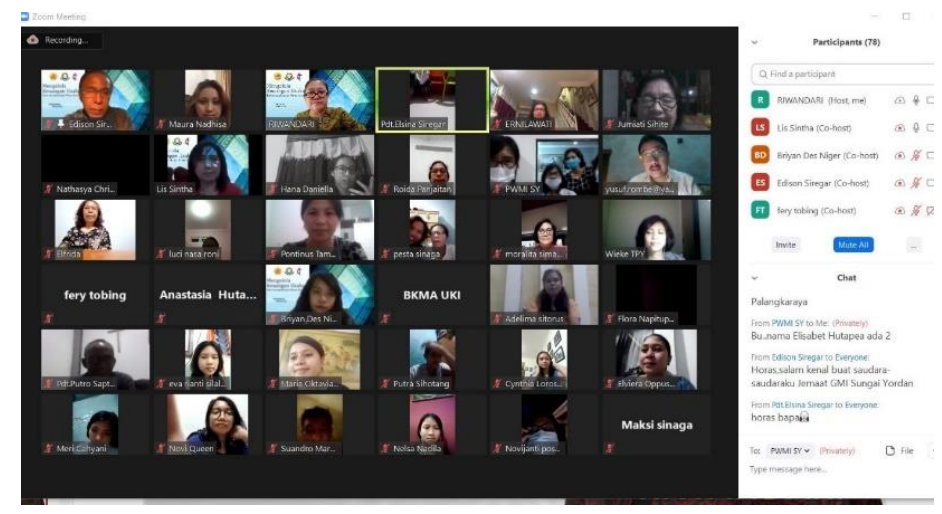

Gambar 1. PKM secara online di PWMI melalui Zoom Meeting Sumber: Dokumentasi Pribadi
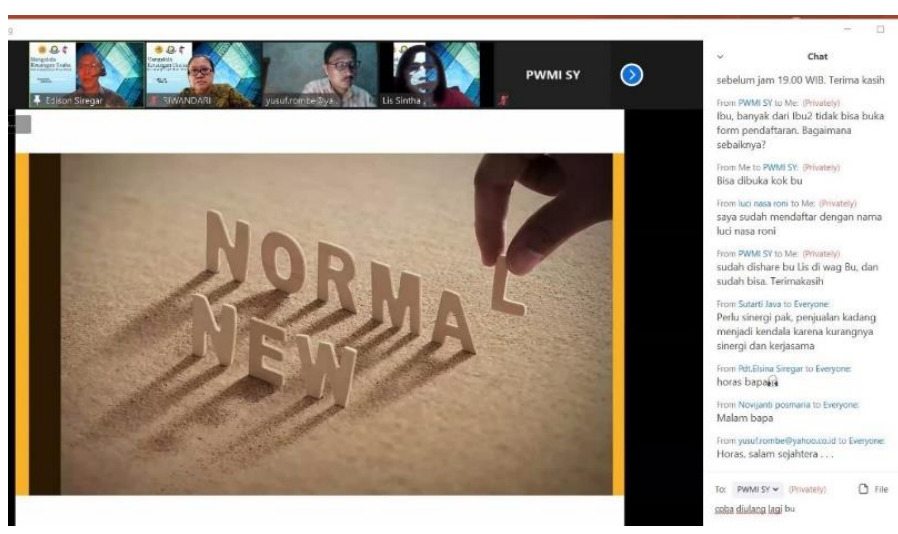

Gambar 2. Pelaksanaan Pemberian Materi 
Sumber: Dokumentasi Pribadi

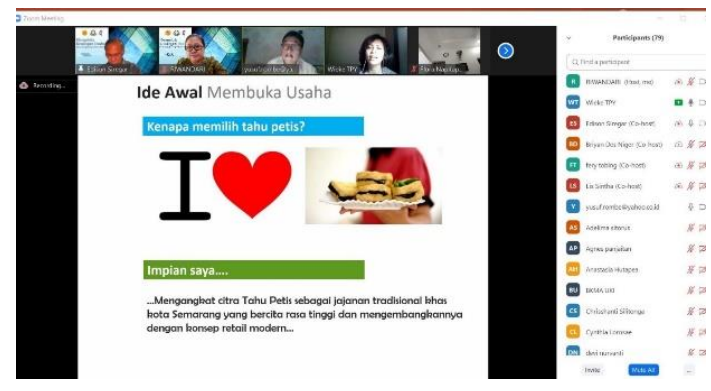

Gambar 3. Presentasi dari lbu Wieke Anggraini pemilik tahu petis Yudhistira Sumber: Dokumentasi Pribadi

Materi yang disampaikan pada saat PKM adalah:
a. Pengenalan usaha/bisnis sampingan dengan modal kecil (Fery Tobing)

b. Prilaku Konsumen di Era New Normal (Edison Siregar)

c. Analisis Break Even Point (Lis Sintha)

d. Cara Mengelola Laba Usaha (Riwandari Juniasti)

Materi yang disampaikan sesuai dengan hasil diskusi dengan PWMI tentang kebutuhan sosialisasi mengelola keuangan usaha.

Sosialisasi dan edukasi dilakukan dengan cara memaparkan materi edukasi tersebut oleh para dosen yang ikut serta dalam PKM ini. Pada saat memaparkan pengenalan usaha/bisnis sampingan dengan modal kecil juga di berikan contoh-contoh usaha sampingan apa saja yang dapt dilakukan dengan modal yang kecil. Kemudian agar peserta makin mengetahui kondisi konsumen saat ini maka diberikan pengetahuan tentang perilaku konsumen di era new normal ini. Untuk meningkatkan pengetahuan dalam menentukan harga dan menghitung BEP maka disampaikan juga materi tentang Analisis Break Even Point. Atas laba yang telah diperoleh, para ibu rumah tangga ini juga dibekali pengetahuan untuk mengelola laba usaha. Pemilik tahu petis Yudhistira juga menceritakan pengalamannya bagaimana awal mengelola usaha, termasuk usahanya dalam misahkan uang usaha dengan uang rumah tangga. Pemilik tahu petis tersebut mengakui bahwa pada awalnya sulit untuk memisahkan keuangan usaha dan keuangan rumah tangga, namun setelah memisahkan rekening usaha dan rekening rumah tangga, membuatnya lebih mudah melakukan pemisahan keuangan tersebut.

Dari Pelaksanaan Pengabdian Masyarakat di PWMI dapat diketahui hal-hal berikut ini:

a. Peserta sudah menyadari pentingnya pemisahan keuangan 
keluarga dan keuangan usaha, namun pemisahan tersebut tidak dapat berlangsung lama, sering berakhir kembali dengan tercampurnya keuangan keluarga dan usaha.

b. Melakukan pencatatan keuangan bukan merupakan hal yang prioritas, yang menjadi prioritas adalah usaha tetap berjalan dan menghasilkan.

c. Masih kurangnya pemahaman bagaimana melakukan pencatatan keuangan yang baik, sehingga pencatatan lebih pada pencatatan uang keluar masuk saja, sehingga sulit melakukan analisa terhadap usaha dari hasil pencatatan tersebut. tumbuhnya usaha selain fokus pada pemasaran. Oleh karena itu untuk menyelesaikan masalah ini perlu memberikan pemahaman akuntansi dasar

d. Bagi yang sudah memahami laporan keuangan dan mengerti manfaat laporan keuangan, kendalanya adalah kurangnya komitmen untuk melakukan pencatatan dengan tertib.

e. Peserta memahami bahwa laba usaha perlu dikelola namun belum memahami bagaimana cara mengelolanya. Sehingga pemberian materi mengenai cara mengelola usaha sudah sesuai dengan kebutuhan.

\section{SIMPULAN}

1. Anggota perkumpulan yang mengikuti acara penyuluhan dan edukasi ini memerlukan pendampingan untuk menjalankan usaha sampingan yang sesuai dengan kemampuan masingmasing peserta.

2. Perlu adanya pelatihan tentang pencatatan keuangan dan menganalisa pencatatan keuangan tersebut. Pelatihan ini dapat berupa pelatihan mengenai dasar-dasar akuntansi dapat juga anggota perkumpulan ini diperkenalkan pada aplikasi-aplikasi pembukuan yang sekarang sudah banyak ditawarkan kepada masyarakat.

\section{UCAPAN TERIMA KASIH}

Terlaksananya kegiatan Pengabdian Pada Masyarakat Program Studi Perbankan dan Keuangan Fakultas Vokasi Universitas Kristen Indonesia pada kelompok ibu-ibu Persekutuan Wanita Methodist Indonesia (PWMI) pada tanggal 18 November 2020 yang dilaksanakan secara online, tidak lepas dari peran dan dukungan dari: 
1. Bapak Pdt. Ompon Tambunan selaku Pimpinan Jemaat GMI Sungai Yordan Bekasi

2. Ibu Pdt. Rinne Siregar selaku Penanggungjawa PWMI GMI Sungai Yordan Bekasi

3. Ibu Lolo Saidah Hutapea selaku Ketua PWMI GMI Sungai Yordan Bekasi

4. Ibu Wieke Agraini selaku Owner Tahu Petis Indonesia

5. Bapak Maksimus Bisa, SSt., Ft., SKM., M.Fis selaku Dekan Fakultas Vokasi

6. Bapak Fery Tobing, SE., MM selaku Ketua Program Studi Perbankan dan Keuangan

atas kesempatan dan dukungannya kami mengucapkan terima kasih. Kami telah diberi kesempatan untuk memperkenalkan kepada peserta bisnis sampingan yang dapat dilakukan dan bagaimana mengelola keuangan usaha sebagai wujud Tridharma Perguruan Tinggi dalam pengabdian pada masyarakat.

\section{REFERENSI}

Brigham, E., \& Houston, J. 2009. Fundamentals of Financial Management (12 ed.). USA: Soth Western
Chistina Irwati Tanan \& Dian Dhamayanti. 2020. Pendampingan UMKM dalam Pengelolaan Keuangan Usaha Guna Peningkatan Ekonomi Masyarakat di Distrik Abepura Jayapura. Indonesian Journal of Community Research and Engagement. Vol 1, No.2, 2020. 173-184

Edy Supriyono, dkk .2021. Pengelolaan Keuangan Keluarga Pada lbu Rumah Tangga Pemilik UMKM Sebagai Masyarakat Terdampak Covid-19 Di Kelurahan Kauman, Surakarta. Jurnal Budimas Vol.03, No.01, 2021.

Heri Junaidi., Ibu Rumah Tangga: Streotype Perempuan Pengangguran., Jurnal Kajian Gender dan Anak Volume 12, Nomor 01, Juni 2017

Khadijah et.all., Literasi Informasi Motivasi Berwirausaha lbu Rumah Tangga Kelurahan Nagasari Kabupaten., Jurnal Kajian Informasi \& Perpustakaan Vol.4/No.2, Desember 2016

RJ Purnama, E Siregar, LS Oppusunggu, F Tobing, Peningkatan Literasi Terhadap Lembaga Jasa Keuangan Bank Pada Masyarakat Kelurahan Cawang Jakarta Timur, JURNAL 
ComunitÃ Servizio, olume 2, Nomor 2, Tahun 2020 Hal 429 436

Susanti, dkk (2019). Strategi UMKM di Masa Pandemi Covid-19. Jurnal Karya Ilmiah Pengabdian Masyarakat volume 2 No. 1.

Strategi Nasional Literasi Keuangan

(Revisit 2017), Otoritas Jasa Keuangan

Widiyati, I. 2012. Faktor-Faktor yang Mempengaruhi Literasi Finansial Mahasiswa Fakultas Ekonomi dan Bisnis Universitas Brawijaya. Jurnal Akuntansi dan Pendidikan. 1 (1).

Yulianti, N dan M. Silvy. 2013. Sikap Pengelolaan Keuangan Dan Perilaku Perencanaan Investasi Keluarga Di Surabaya. Journal of Business and Banking. 3 (1): 57 68. 